\title{
Lentivirally engineered dendritic cells activate AFP-specific T cells which inhibit hepatocellular carcinoma growth in vitro and in vivo
}

\author{
YANG LIU ${ }^{1}$, LISA H. BUTTERFIELD ${ }^{3}$, XIAOHUI FU ${ }^{2}$, ZHENSHUN SONG ${ }^{1}$, \\ XIAOPING ZHANG ${ }^{1}$, CHONGDE LU ${ }^{2}$, GUANGHUI DING ${ }^{1}$ and MENGCHAO WU ${ }^{2}$
}

\begin{abstract}
${ }^{1}$ Department of Hepatobiliary Surgery, Shanghai 10th People's Hospital Affiliated to Tongji University, Shanghai 200072;
${ }^{2}$ Department of Hepatobiliary Tumor, Eastern Hepatobiliary Surgery Hospital, Shanghai 200433, P.R. China; ${ }^{3}$ Departments of Medicine, Surgery and Immunology, University of Pittsburgh Cancer Institute, University of Pittsburgh, PA 15213, USA
\end{abstract}

Received November 4, 2010; Accepted December 20, 2010

DOI: 10.3892/ijo.2011.1004

\begin{abstract}
AFP), a tumor-associated antigen for hepatocellular carcinoma (HCC), is an established biomarker for HCC. In this study, we created a lentivirus expressing the AFP antigen and investigated the anti-tumor activity of AFP-specific $\mathrm{CD}^{+} \mathrm{T}$ cells, with and without $\mathrm{CD} 4^{+} \mathrm{T}$ cells, which were activated by either AFP peptide-pulsed or LentiAFP-engineered Dendritic cells (DCs) in vitro and in vivo. AFP-specific T cells could efficiently kill HepG2 HCC cells, and produced IL-2, IFN- $\gamma$, TNF- $\alpha$, perforin and granzyme B, with minimal production of IL-10 (a negative regulator of $\mathrm{T}$ cell activation). Both strategies activated AFP-specific T cells, but the lentiviral strategy was superior by several measures. Data also support an impact of CD4 ${ }^{+} \mathrm{T}$ cells in supporting anti-tumor activity. In vivo studies in a xenograft HCC tumor model also showed that AFP-specific T cells could markedly suppress HCC tumor formation and morbidity in tumorbearing nude mice, as well as regulate serum levels of related cytokines and anti-tumor molecules. In parallel with human in vitro $\mathrm{T}$ cell cultures, the in vivo model demonstrated superior anti-tumor effects and Th1-skewing with Lenti-AFP-DCs. This study supports the superiority of a full-length antigen lentivirus-based DCs vaccine strategy over peptides, and provides new insight into the design of DCs-based vaccines.
\end{abstract}

\section{Introduction}

Hepatocellular carcinoma (HCC) is one of the main causes of cancer deaths with a global incidence of over 500,000 new

Correspondence to: Dr Yang Liu, Shanghai 10th People's Hospital Affiliated to Tongji University, Shanghai 200072, P.R. China

E-mail: yliu6633@yahoo.com.cn

Dr Lisa H. Butterfield, University of Pittsburgh, 1.27 Hillman Cancer Center 5117 Centre Avenue, Pittsburgh, PA 15213, USA

E-mail: butterfieldl@upmc.edu

Key words: $\alpha$-fetoprotein, dendritic cell, cytokine, AFP, T cells cases per year. HCC has a very poor prognosis, and the majority of cases are detected at advanced stages (1). Systemic therapies, including chemotherapy, are largely ineffective. Local-regional therapy other than resection is largely palliative and includes: Yttrium, transcatheter arterial chemoembolization (TACE), cryoablation and radiofrequency ablation (RFA). The recently US FDA-approved drug, sorafenib, improved median overall survival (OS) by $2.8 \mathrm{mo}$. (10.7 mo. vs. $7.9 \mathrm{mo}$. in the placebo group) in unresectable, advanced disease patients (2). Therefore, novel approaches are needed, and immunotherapy interventions that directly target tumor specific antigens (TSA) or tumor-associated antigens (TAA) are a current research focus (3). $\alpha$-fetoprotein (AFP), which belongs to the albuminoid gene family, is a main component of serum during embryonic development. AFP, a 69-kDa single-chain polypeptide, consisting of 591 amino acid residues, is synthesized in the yolk sac, fetal liver, and gastrointestinal tract during pregnancy $(4,5)$. Suppression of AFP synthesis occurs shortly after birth (6), however, $50 \%$ to $80 \%$ of adult HCC show AFP re-expression during tumor progression at levels from $10 \mathrm{ng} / \mathrm{ml}$ to $1 \mathrm{mg} / \mathrm{ml}$ $(7,8)$. These observations suggest that inducing AFP-specific immune responses might be an important direction for clinical treatment of HCC.

Dendritic cells (DCs) are acknowledged as the most powerful professional antigen-presenting cells. They are central to the initiation of an immune response and play vital roles in antitumor immunity $(9,10)$. Clinical studies have shown that DCs infiltration in solid tumors correlated with better prognosis while impaired DCs function can inhibit immune responses to tumor (11-13). Thus, DC-based tumor immunotherapy may help to reverse aspects of tumor-driven immune dysfunction and promote anti-tumor immunity. Recently, the first DC-related cancer vaccine received US FDA approval for prostate cancer therapy (Dendreon, 'Provenge'). In order to generate tumorspecific immune responses against HCC, AFP has been targeted by our group and others. Based on our in vitro human $\mathrm{T}$ cell assays and HLA-A2 transgenic mouse studies, the human T cell repertoire responds to the human AFP 'self' antigen, and four immunodominant and ten subdominant epitopes were identified $(14,15)$. 
A pilot clinical trial was performed in which HCC patients received the four immunodominant peptides emulsified in adjuvant. Five of six patients showed an increased circulating frequency of AFP peptide-specific T cells (by MHC tetramer) to at least one of the peptides. IFN- $\gamma$ ELISPOT results demonstrated development of functional cytokine responses to all four peptides after vaccination. Most of the pre-treatment AFP-specific cells detected by MHC tetramer assays did not synthesize IFN- $\gamma$ until after vaccination (16). Because murine models testing murine AFP suggest that AFP-based vaccines are capable of reducing tumor growth $(15,17,18)$, a follow-up trial using AFP peptide-pulsed DC was performed. Ten stage III/stage IV AFP+-HLA-A2.1+ HCC subjects were vaccinated with AFP peptide-pulsed autologous DCs (19). Again, increased frequencies of circulating AFP-specific T cells and of IFN- $\gamma$ producing AFP-specific T cells were detected after vaccination. However, this vaccine did not result in objective clinical responses in that group of advanced stage patients.

An analysis of the differentiation status of circulating AFP-specific $\mathrm{CD} 8^{+} \mathrm{T}$ cells showed an expanded pool of naive and central memory AFP-specific $\mathrm{CD}^{+}{ }^{+} \mathrm{T}$ cells in many $\mathrm{HCC}$ patients which co-express central and peripheral trafficking markers, indicating only partial differentiation. Peptide-based vaccination (in the AFP peptide/DC trial) led to modest upregulation of activation markers, but most patients showed no shifts to fully differentiated effector or memory cells (20). In order to address the possibility that only low avidity AFP-specific $\mathrm{T}$ cells are available in the periphery of humans activated by vaccines, AFP-specific T cell avidity was tested (21) and it was determined that some AFP-specific T cells are of sufficiently high avidity to recognize very low levels of peptide as well as AFP-expressing tumor cells.

Next, to illustrate the potential relevance of both immunodominant and subdominant AFP epitopes, full-length antigen-based strategies were investigated. Full length AFP presentation revealed that $\mathrm{HCC}$ patients have detectable frequencies of circulating IFN- $\gamma$-producing AFP-specific $\mathrm{CD}^{+} \mathrm{T}$ cells to both immunodominant and subdominant epitopes. The immunodominant and subdominant peptidespecific $T$ cells could be differentially expanded with different modes of antigen presentation (21) and adenovirally-transduced DCs (AdV/DCs), expressing full-length antigen, were superior to other antigen presentation modes for broad expansion of high frequencies of multiple $\mathrm{CD}^{+} \mathrm{T}$ cell clones. The subdominant epitope-specific $\mathrm{CD} 8^{+} \mathrm{T}$ cells could also recognize tumor cells and may be important therapeutically.

AdVhAFP-transduced DCs have been shown to efficiently activate AFP-specific $\mathrm{CD}^{+}$and $\mathrm{CD} 4^{+} \mathrm{T}$ cell responses $(17,20,22)$. However, gene transfer mediated by adenovirus has several potential weaknesses. In cells which proliferate, the gene transfer is transient due to the lack of $\mathrm{AdV}$ integration. Also, AdV is highly immunogenic, and the transduced DCs process and present virally-derived peptide epitopes which can serve as recall antigens for those environmentally exposed to this virus. Lastly, DCs do not express the Coxackie-Adenovirus Receptor, therefore AdV transduction is not very efficient, requiring a high pfu:cell ratio (MOI), in the range of 500-1,000 to 1 . Thus, in this study, we chose a lentivirus vector, which results in permanent transduction due to viral integration, and reduced immunogenicity (23).
Here, we report the cloning and testing of a lentivirus expressing full-length AFP. We find that co-culturing LentiAFP-engineered or peptide-pulsed DCs with human peripheral blood $\mathrm{T}$ cells, results in AFP-specific T cell immune responses (proliferation, cytokine production, cytotoxicity). We examined their anti-tumor activity in a HepG2 tumor-bearing nude mouse model and found that Lenti-AFP-DC promote superior type 1, cytotoxic anti-tumor immunity against HCC which is more potent than peptide-pulsed DCs. This study provides new insight for the design of antigen-engineered DCs based trials, and the function of the activated AFP antigenspecific T cells for HCC immunotherapy.

\section{Materials and methods}

Healthy donors. All donors were HLA-A*0201 positive according to standard HLA sero-typing and/or genotyping procedures. Informed consent for participating in this study was obtained from all donors.

Animals and cell lines. Nude mice (6-8 weeks old) were purchased from Shanghai Life Scientific Academy (SLSA). Mice were housed under specific pathogen-free conditions. All experiments were carried out according to the National Institutes of Health Guide for Care and Use of Laboratory Animals and were approved by the Bioethics Committee of SLSA. The HLA-A2+ AFP-expressing HCC cell line HepG2 was obtained from American Type Culture Collection.

Peptide synthesis. Peptides were synthesized by Sangon Biological Engineering Technology and Service Co. (Shanghai, China). Amino acid sequences were confirmed by amino acid analysis and mass spectroscopy. The purity of the peptides was greater than $95 \%$. The peptides used are as follows: $\mathrm{AFP}_{1}=\mathrm{MKWVESIFL}, \mathrm{AFP}_{137}=\mathrm{PLFQVPEPV}, \mathrm{AFP}_{158}=$ FMNKFIYEI, $A_{F P} P_{325}=$ GLSPNLNRFL, $A_{4 P_{492}=}$ PVNPGVGQC, $A_{F P_{542}}=$ GVALQTMKQ, $A_{F P} P_{547}=$ TMKQEFLINL.

Construction and preparation of recombinant lentiviral vectors. The lentiviral vector, pWPXL-MOD2, which expresses green fluorescent protein (GFP) was used as the backbone for lentiviral vector construction in this study. $\alpha$ fetoprotein (AFP) coding sequences were amplified by PCR from HepG2 template and both BamH1 and Sal1 flanking site sequences were introduced. After digestion of PCR products with BamH1 and Sal1, the coding sequence for AFP was purified with a gel purification kit (Invitrogen, Carlsbad, CA) following the manufacturer's instruction. The DNA coding for these proteins were subsequently cloned in pWPXL-MOD2 vector earlier digested with BamH1 and Sal1 and gel purified. Preparation of lentiviruses was accomplished using the ProFection Mammalian Transfection System (Promega) according to manufacturer's instructions with some modifications. Briefly, cells cultured in DMEM (Gibco-Invitrogen, Carlsbad, CA) containing $10 \%$ fetal bovine serum (HyClone, Logan, UT), $100 \mathrm{U} / \mathrm{ml}$ of penicillin, and $100 \mathrm{mg} / \mathrm{ml}$ streptomycin (GibcoInvitrogen), were co-transfected with appropriate amounts of the lentiviral vector plasmid, pRSv-REV, pMD1g-pRRE, pMD2G, and interfere plasmid. Into these mixtures, $200 \mu 1$ of 
$\mathrm{CaCl}_{2}(2.5 \mathrm{M}, \mathrm{pH}$ 7.2) was added. The DNA-calcium complexes were further mixed with 2,000 $\mu \mathrm{l}$ of $2 \mathrm{X}$ HEPES buffered solution for $30 \mathrm{~min}$ at room temperature. The mixtures were subsequently added to $6 \mathrm{ml}$ culture medium in a $10-\mathrm{cm}$ Petridish containing 293T cells at a density of 60-70\%. After $12 \mathrm{~h}$, the medium was replaced with $15 \mathrm{ml}$ of phenol red-free and fetal bovine serum-free Dulbecco's modified Eagle's medium. The supernatant was collected $72 \mathrm{~h}$ later and the cell debris was cleared by centrifugation at $3,750 \mathrm{x}$ g for $5 \mathrm{~min}$ at $4^{\circ} \mathrm{C}$ in a bench top centrifuge (Beckman, Fullton, CA). The clear supernatants were filtered through a $0.45-\mu \mathrm{m}$ filter and then used to infect cells directly or after further concentration by ultra-centrifugation $(72,000 \mathrm{x}$ g for $120 \mathrm{~min}$ at Beckman ultracentrifuge with the rotor S28), and then resuspended in phosphate buffered saline and kept at $-80^{\circ} \mathrm{C}$ until usage. Viral titers were determined by infecting $293 \mathrm{~T}$ cells with different dilutions of the vectors and measuring GFP expression by flow cytometry. AFP transgene expression was measured at both RNA (RT-PCR) and protein levels (Fig. 1). Human DCs were transduced at MOI (multiplicity of infection) $=10$, and after $72 \mathrm{~h}$, tested for AFP mRNA by real-time PCR with the following primers (Forward: 5'-ATT TGG ATC CCG CCA CCA TGA AGT-3'; Reverse: 5'-AGA CGT CGA CTC ATT AAA CTC CCA-3'). AFP protein was detected by Western blot in human DC using an AFP specific antibody (R\&D Systems).

Generation of DC and DC culture. DCs were prepared as previously described $(24,25)$. In brief, peripheral blood was drawn by venous puncture or leukapheresis, and lymphocytes were purified by Ficoll (Pharmacia) gradient separation. PBMC (3-4X107) were cultured in T-25 flasks (Costar) in RPMI-1640 in addition with antibiotics and 5-10\% human AB serum for $2 \mathrm{~h}$ at $37^{\circ} \mathrm{C}$ in a humidified $\mathrm{CO}_{2}$ incubator. The non-adherent cells were gently removed with PBS, and the loosely adherent cells were cultured in medium with $800 \mathrm{U} / \mathrm{ml}$ GM-CSF (R\&D Systems) and 500 U/ml IL-4 (R\&D Systems) for 7 days. The non-adherent and loosely adherent DCs were harvested by vigorous washing. These cells generally consisted of 30-50\% DC as assessed by morphology and phenotyping. No further maturation treatments were performed to avoid potential Th1/Th2 skewing of T cell responses.

Purification of $C D 8^{+} T, C D 4^{+} T$ cells from $P B M C . \mathrm{CD}^{+} \mathrm{T}$ and $\mathrm{CD}^{+}{ }^{+} \mathrm{T}$ cells from HLA-A2 ${ }^{+}$donors were positively selected using anti-CD4 isolation and anti-CD8 isolation kit (Dynal, Biotech), respectively. The purity of the resulting $\mathrm{CD}^{+} \mathrm{T}$ and $\mathrm{CD}^{+} \mathrm{T}$ cell populations were examined by flow cytometry with CD4-FITC, CD8-PE, CD14-PE, and CD19-PE antibodies and found to be consistently $>95 \%$.

Generation of AFP-specific $C D 8^{+} T$ and $C D 4^{+} T$ cells from peptide-pulsed or lenti-transduced DC. Peptide-specific $\mathrm{CD}^{+} \mathrm{T}$ and $\mathrm{CD}^{+} \mathrm{T}$ cells were prepared as previously described $(15,26,27)$. Briefly, DCs from HLA-A2+ donors were pulsed with AFP peptides at $10 \mu \mathrm{g} / \mathrm{ml}$ in serum-free RMPI-1640 at room temperature for $2 \mathrm{~h}$. DCs were plated in wells of a 24-well plate at a 1:20 ratio with autologous $\mathrm{CD}^{+} \mathrm{T}$ or $\mathrm{CD}^{+} \mathrm{T}$ cells in $10 \% \mathrm{AB}$ serum/RPMI-1640/penicillin-streptomycin with $10 \mathrm{ng} / \mathrm{ml} \mathrm{IL-7} \mathrm{(R \& D)} \mathrm{for} 1$ week, and supplemented with IL-2 (Sigma) at $10 \mathrm{U} / \mathrm{ml}$ every 3-4 days. After one week culture, the non-adherent cells were counted and restimulated with fresh or thawed DC pulsed with the same peptide. After two restimulations, cells were harvested for analysis.

DCs were transduced with Lenti-AFP or Lenti-LacZ at a multiplicity of infection (MOI) of 10 for $2 \mathrm{~h}$ (22). Transduced DCs were washed and plated at $1 \times 10^{5}$ cells $/ \mathrm{ml}$ to serve as stimulators for AFP-specific T cells generation. Purified autologous $\mathrm{CD}^{+} \mathrm{T}$ or $\mathrm{CD}^{+} \mathrm{T}$ cells were plated with the transduced DCs at $2 \times 10^{6}$ cells $/ \mathrm{ml}$ in $10 \% \mathrm{AB}$ serum in the presence of IL-7 $(25 \mathrm{ng} / \mathrm{ml})$. Cultures were supplemented with IL-2 at $10 \mathrm{U} / \mathrm{ml}$ every 3 days. Cells were harvested after culture for 7 days.

Cytotoxicity assay. Cytotoxicity was assessed by MTT assay as preciously described (28). In brief, AFP specific $\mathrm{CD}^{+} \mathrm{T}$ cells with or without $\mathrm{CD}^{+} \mathrm{T}$ cells were co-cultured with equal number of HepG2 cells in triplicate for $24 \mathrm{~h}$. Lymphocytes and target cells cultured with media alone were used as controls. MTT $(5 \mathrm{mg} / \mathrm{ml})$ reagent was added $6 \mathrm{~h}$ before the end of culture, and then cells were lysed with $100 \mu$ l DMSO. Values (A) were read at $570 \mathrm{~nm}$, and the percentage of cytotoxicity was calculated as below: Cytotoxicity $(\%)=[1-$ $\left.\left(\mathrm{A}_{\text {sample }}-\mathrm{A}_{\text {Lymphocyte control }}\right) / \mathrm{A}_{\text {target cell control }}\right] \times 100 \%$.

Lymphocyte proliferation assay. Cells (2x105/well) were cultured in triplicate in $200 \mu \mathrm{l}$ of RPMI-1640 in addition with antibiotics and $10 \%$ human $\mathrm{AB}$ serum. For proliferation, cells were pulsed with $1 \mu \mathrm{Ci} /$ well $\left[{ }^{3} \mathrm{H}\right]$-thymidine for $6 \mathrm{~h}$ before harvest and assessed for $\left[{ }^{3} \mathrm{H}\right]$-thymidine incorporation. Results are showen as Stimulate Index (SI):

$\mathrm{SI}=\mathrm{cpm}$ (sample)/cpm (control). PHA mitogen stimulation (5 $\mu \mathrm{g} / \mathrm{ml})$ and Lenti-LacZ transduced DC stimulation ('blank') served as positive and negative controls, respectively.

Cytokine measurement. Cells (2x105/well) were cultured in triplicate in $200 \mu \mathrm{l}$ of RPMI-1640 in addition with antibiotics and $10 \%$ human $\mathrm{AB}$ serum. After $24 \mathrm{~h}$, culture supernatants were harvested and stored at $-20^{\circ} \mathrm{C}$. Concentrations of IL-2, IFN- $\gamma$, TNF- $\alpha$, IL-10, perforin and Granzyme B were determined by ELISA as described by the manufacturer (R\&D system).

Murine tumor studies. Tumors were generated by subcutaneous injection of $10^{6} \mathrm{HepG} 2$ cells in $0.1 \mathrm{ml}$ of PBS into the flank of each nude mouse. Mice were divided into four groups according to body weight (10 mice per group): i) Lenti-AFP group, which was simultaneously treated with $\mathrm{T}$ cells activated by Lenti-AFP-transduced DC ( $1 \times 10^{6}$ per mouse $)$, ii) $\mathrm{AFP}_{542}$ or $\mathrm{AFP}_{1}$ group, mice were subcutaneously injected of $10^{6} \mathrm{~T}$ cells activated by $\mathrm{AFP}_{542}$ or $\mathrm{AFP}_{1}$ peptide-pulsed DC, iii) in the control group, mice were subcutaneously injected with $200 \mu \mathrm{l}$ of PBS. After two weeks, tumor tissues were collected for measuring tumor diameter and weight. Serum was used for cytokine profile analysis.

Tumor treatment in vivo. When the largest tumor diameter exceeded $3 \mathrm{~mm}$, mice were injected intratumorally with $10^{6} \mathrm{~T}$ cells that treated with Lenti-AFP transduced DC, $\mathrm{AFP}_{542^{-}}$ pulsed DC, or $\mathrm{AFP}_{1}$-pulsed DC in $100 \mu \mathrm{l}$ PBS. Mice intratumorally injected with $100 \mu \mathrm{l} \mathrm{PBS} /$ mouse were used as the control. Each group contained 10 mice. The mice were 
A

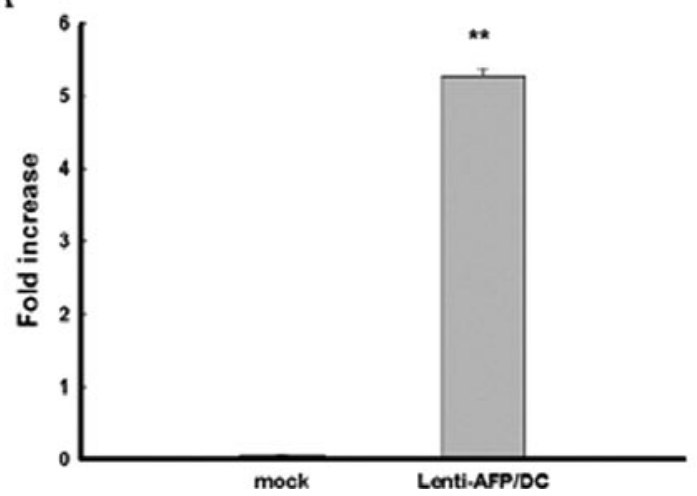

B

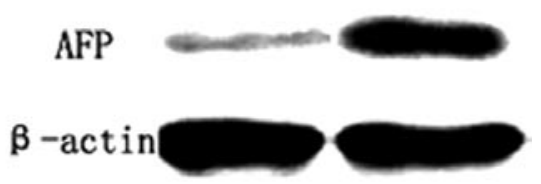

Figure 1. Lentivirus transfection rate and AFP expression level in 293T cells. (A) AFP expression in lentivirus-transfected DC; 18sRNA serves as internal control. (B) Western blot assay of AFP protein level. Fold increase is shown as the mean $\pm \mathrm{SD},{ }^{* *} \mathrm{p}<0.01$ compared with negative control ( $\beta$-actin). Three independent experiments were performed with similar results for both RNA and protein tests.

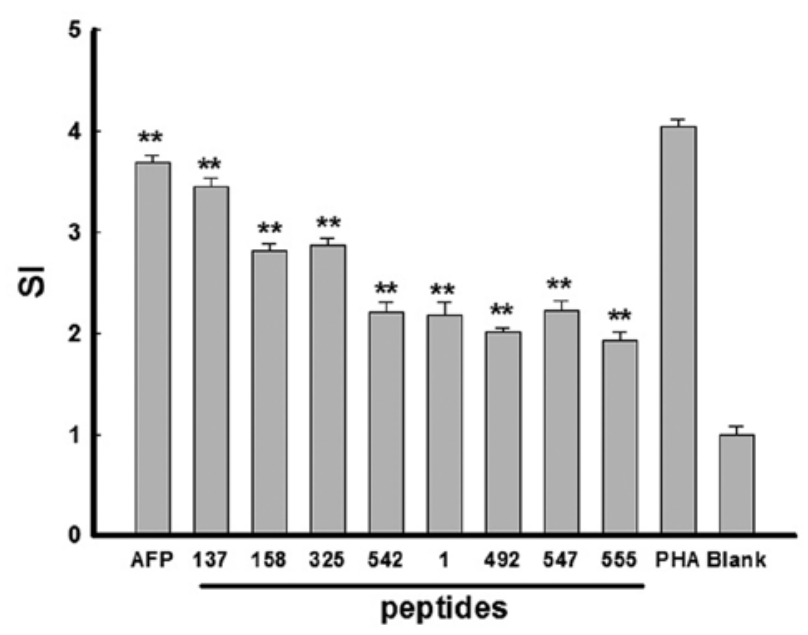

Figure 2. Peptide-pulsed and Lenti-AFP transduced DC significantly induce $\mathrm{T}$ cell proliferation. DCs were pulsed with AFP peptides at $10 \mu \mathrm{g} / \mathrm{ml}$ or transduced with Lenti-AFP ('AFP') or Lenti-LacZ ('blank'). DCs were plated in a 96-well plate at a 1:20 ratio with autologous T cells for 3 days. Cells were pulsed with $1 \mu \mathrm{Ci}$ /well $\left[{ }^{3} \mathrm{H}\right]$-thymidine for $6 \mathrm{~h}$ before harvest and assessed for $\left[{ }^{3} \mathrm{H}\right]$-thymidine incorporation. Results are shown as Stimulate Index (SI): $\mathrm{SI}=$ cpm (sample)/cpm (control). PHA was served as positive control, while LacZ-DC stimulation was served as negative control (blank). Results were shown as the mean $\pm \mathrm{SD},{ }^{* *} \mathrm{p}<0.01$ compared with negative control. Three independent experiments were performed with similar results.

treated once a week for 2 weeks. At the end of the experiment, tumor tissues were collected for measuring tumor diameter and weight. Serum was used for cytokine profile analysis.

Statistical analysis. Results are expressed as mean $\pm \mathrm{SD}$, One-way analysis of variance followed by Dunnett's post test was used to determine differences between groups where appropriate. $\mathrm{p}<0.05$ was considered significant. Significant differences are noted as ${ }^{*} \mathrm{p}<0.05,{ }^{* *} \mathrm{p}<0.01$ and ${ }^{* * *} \mathrm{p}<0.001$.

\section{Results}

Peptide-pulsed and lenti-transduced DCs induce T cell proliferation. In this study, a lentivirus vector expressing fulllength AFP gene was constructed. We first assessed lentivirus

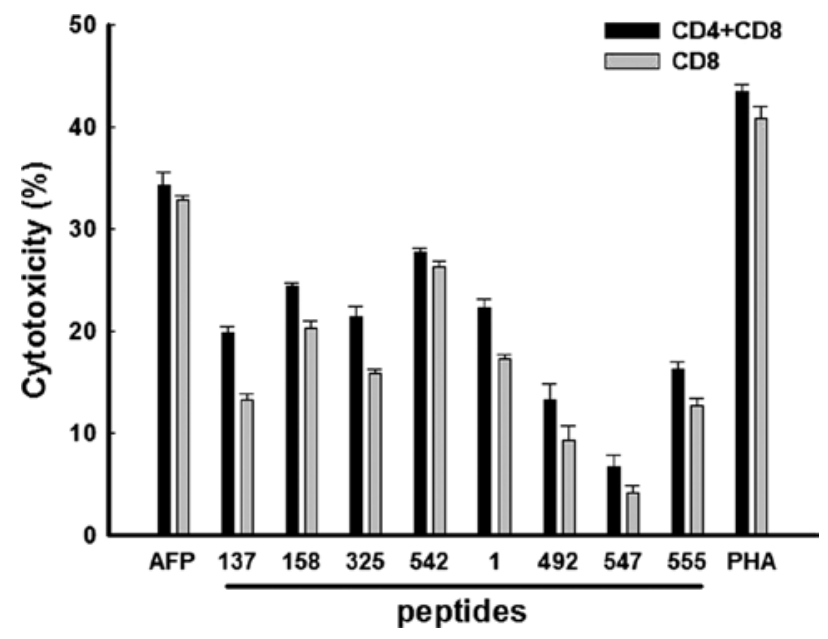

Figure 3. Killing activity of lenti, or peptide-DC-activated AFP-specific $\mathrm{CD}^{+} \mathrm{T}$ cells against HepG2 cells. AFP-specific $\mathrm{CD} 8^{+} \mathrm{T}$ cells (with or without $\mathrm{CD}^{+} \mathrm{T}$ cells) were co-cultured with an equal number of HepG2 cells in triplicate for $24 \mathrm{~h}$. Lymphocytes and target cells cultured with media alone were used as controls. MTT was added $6 \mathrm{~h}$ before the end of the culture. Results were shown as the mean \pm SD. Three independent experiments were performed with similar results.

transfection-mediated AFP mRNA and protein expression levels. The expression of AFP mRNA over baseline is $5.31 \pm$ 0.11 compared with 18sRNA (Fig. 1A), while at the protein level, AFP expression was positive compared with LentiLacZ-transduced group (Fig. 1B). Human DCs were transduced at $77.4 \%$ efficiency at lentiviral MOI of 10 (data not shown).

To investigate the ability of Lenti-AFP-transduced DC to promote anti-tumor immune responses, $\mathrm{T}$ cell proliferation rate was assessed. We compared two methods of antigen presentation, Lenti-AFP-transduced DC and AFP peptidepulsed DC. Results show that Lenti-AFP-transduced DC could significantly promote $\mathrm{T}$ cell proliferation (Fig. 2$)$, ( $\mathrm{SI}=$ $3.68 \pm 0.07, \mathrm{p}<0.01)$. The proliferation induced by peptidepulsed DC was slightly inferior to Lenti-AFP-DC, but each peptide-pulsed DC group tested also reached significance $(\mathrm{p}<0.01)$ over background. Consistent with our previous report (21), we also observed a pattern of hierarchy of AFP-specific 


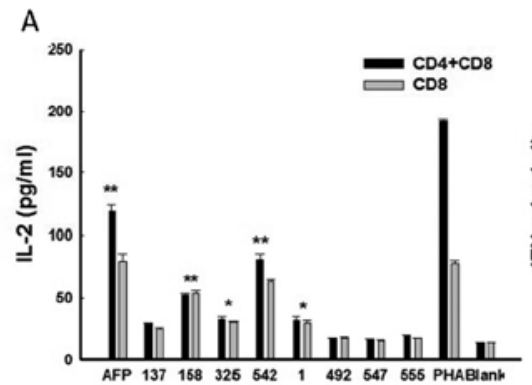

B
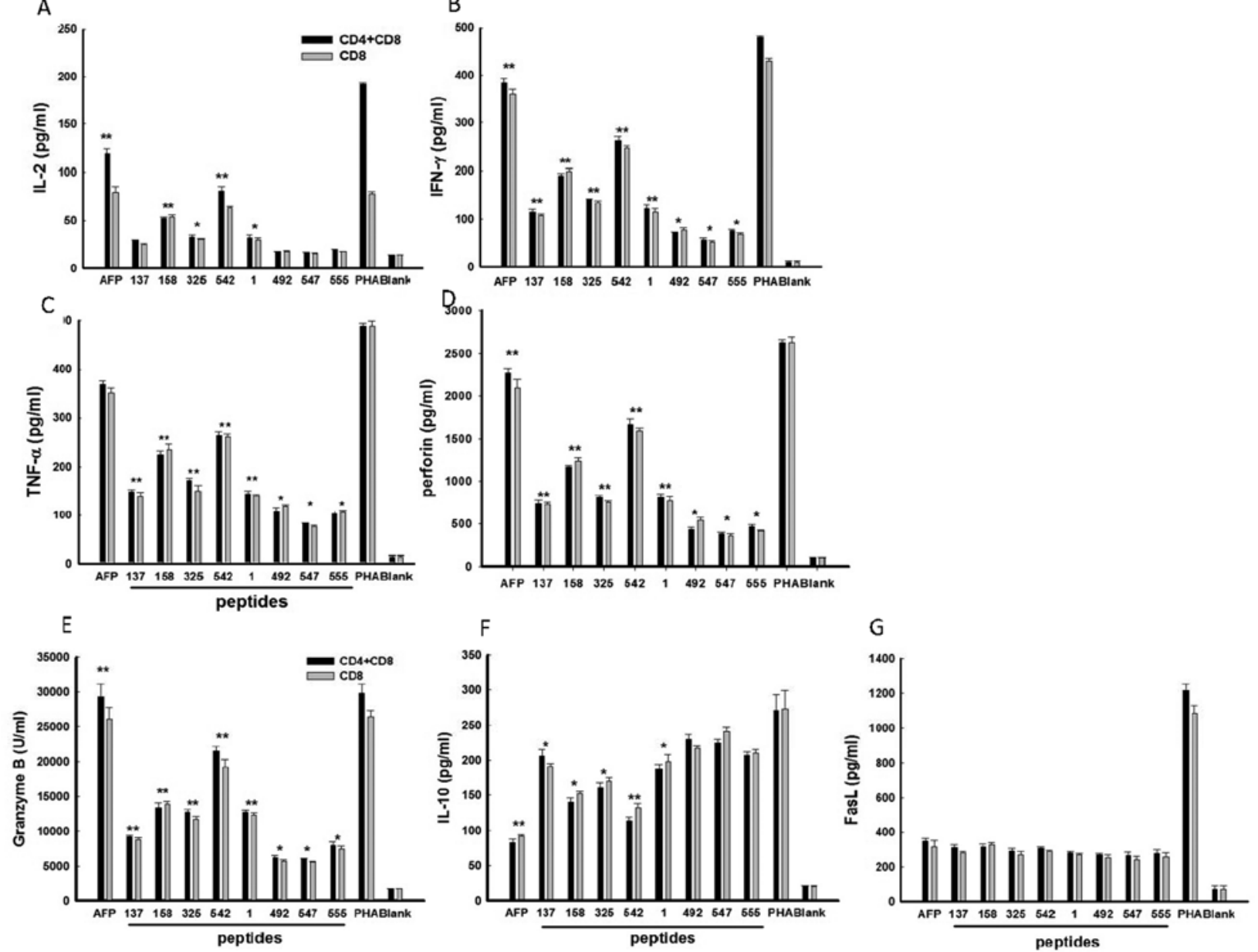

Figure 4. DC-activated AFP-specific CD8 ${ }^{+} \mathrm{T}$ and $\mathrm{CD} 4^{+} \mathrm{T}$ cells increase expression of anti-tumor cytokines and the effector molecule. AFP-specific CD8 ${ }^{+} \mathrm{T}$ cells with or without $\mathrm{CD}^{+} \mathrm{T}$ cells were co-cultured with equal number of HepG2 cells in triplicate for $24 \mathrm{~h}$. Supernatants were collected and tested by ELISA assay. (A) IL-2, (B) IFN- $\gamma$, (C) TNF- $\alpha$, (D) IL-10, (E) Granzyme B, (F) perforin, (G) FasL. Results were shown as the mean \pm SD. Lenti-AFP is 'AFP', LentiLacZ is the negative control ('blank'). Three independent experiments were performed with similar results.

$\mathrm{CD}^{+} \mathrm{T}$ cell responses between immunodominant epitopes $\left(\mathrm{AFP}_{137}, \mathrm{AFP}_{158}, \mathrm{AFP}_{325}, \mathrm{AFP}_{542}\right)$ and subdominant epitopes $\left(\mathrm{AFP}_{1}, \mathrm{AFP}_{492}, \mathrm{AFP}_{547}, \mathrm{AFP}_{555}\right)$ with these healthy donor cells.

AFP-specific $C D 8^{+} T$ cells efficiently kill HepG2 cells. We next evaluated the AFP-specific T cells for cytotoxic function against the HLA-A2 ${ }^{+}, \mathrm{AFP}^{+} \mathrm{HCC}$ cell line HepG2. HepG2 cells were co-cultured with AFP-specific $\mathrm{CD}^{+} \mathrm{T}$ cells only, or co-cultured with AFP-specific $\mathrm{CD}^{+} \mathrm{T}$ and $\mathrm{CD} 4^{+} \mathrm{T}$ cells together; at $1 \mathrm{~T}$ cell:1 tumor cell. After $24 \mathrm{~h}$ (Fig. 3), T cells activated by Lenti-AFP-engineered DC showed the strongest killing activity against HepG2 cells. T cells stimulated with AFP peptide-pulsed DC could efficiently kill target cells as well, while $\mathrm{T}$ cells activated by some of the subdominant AFP peptides on DC showed lower killing activity. We did not observe a statistically-significant difference between AFPspecific $\mathrm{CD}^{+} \mathrm{T}$ cells with $\mathrm{CD}^{+} \mathrm{T}$ cells included and AFP-specific $\mathrm{CD}^{+} \mathrm{T}$ cells-only (although killing activity in the presence of $\mathrm{CD}^{+} \mathrm{T}$ cells was slightly higher), indicating that the effect of $\mathrm{T}$ cell help in this effector phase assay was small (but reproducible between different experimental groups).

Cytokine milieu in Lenti-AFP/DC cultures. In order to characterize the co-culture of AFP-specific $\mathrm{CD}^{+} \mathrm{T}^{+}$and $\mathrm{CD}^{+}$
T cells with HepG2 cells, and determine whether peptidepulsed DC and Lenti-AFP-DC induced a different type 1/ type 2 and cytotoxicity milieu, we assessed the concentration of several cytokines and effector molecules in co-culture supernatants. Results demonstrated that all DC-activated AFP-specific T cells secreted high levels of type 1 cytokines IL-2, IFN- $\gamma$ and TNF- $\alpha$, as well as cytotoxic effector molecules perforin and Granzyme B (Fig. 4). The Lenti-AFP-DC group had the highest levels of these cytotoxic effector molecules, while peptide-pulsed DCs groups had positive, but lower levels. As with the direct killing assay, the differences between $\mathrm{CD}^{+}$ and $\mathrm{CD}^{+}{ }^{+} \mathrm{T}$ cells together and $\mathrm{CD} 8^{+} \mathrm{T}$-cells only were small (with both subsets together again yielding slightly higher effector molecule levels) and not statistically significant. Unexpectedly, CD4 ${ }^{+} \mathrm{T}$ cell inclusion did not significantly increase the cytokine levels, indicating $\mathrm{CD}^{+} \mathrm{T}$ cells were the sources for these molecules.

Also examined was the regulatory cytokine IL-10 (also known to be produced by HepG2 cells) as well as FasL. Importantly, the peptide/DC had some increased levels of IL-10 in the co-culture with HepG2, while the Lenti-AFP-DC has the lowest level. This may be due to a maturation effect of lentivirus transduction on the DC (which we observed earlier with adenoviral transduction of human DC) (29). The Lenti- 

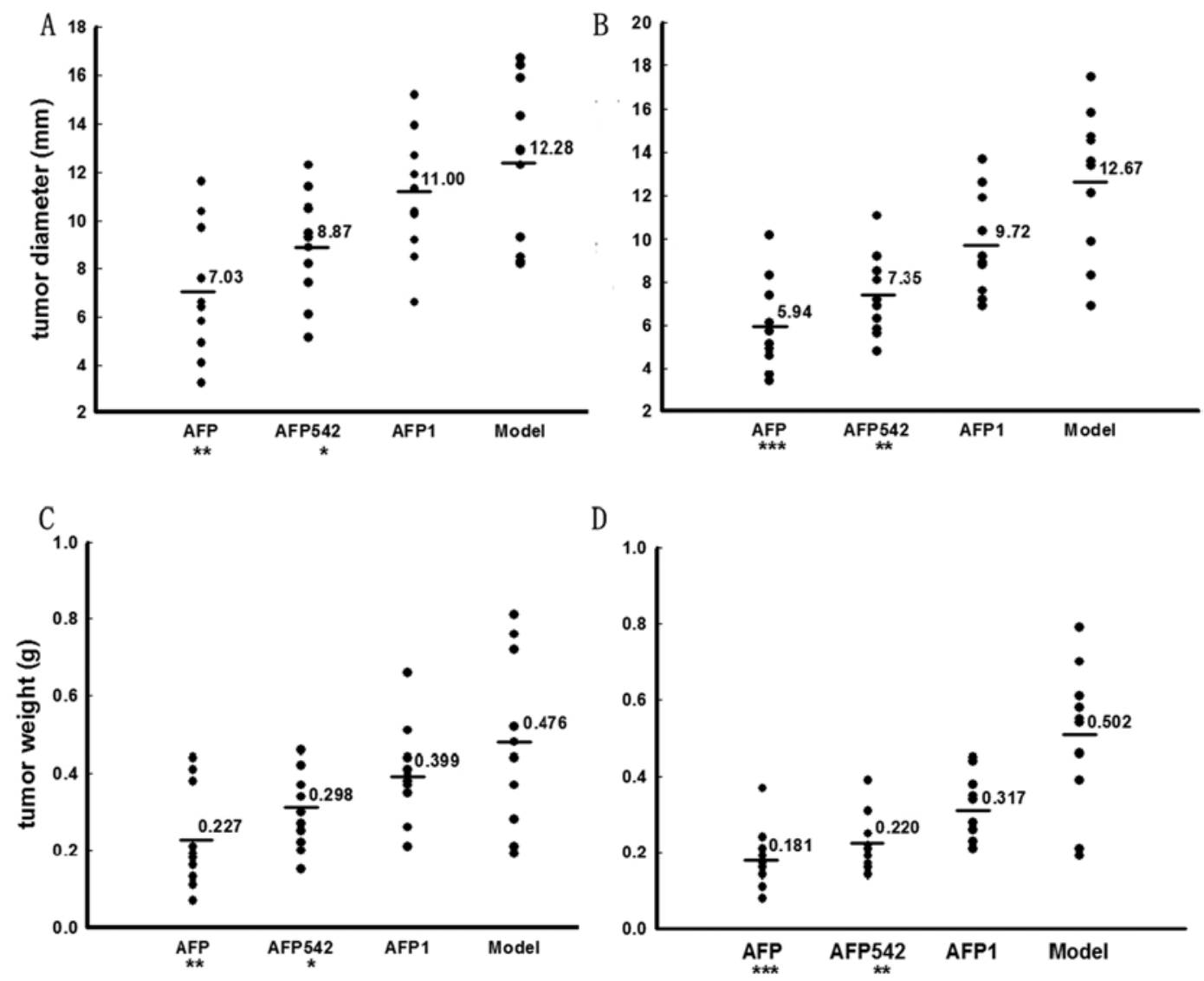

Figure 5. AFP-specific CD8 ${ }^{+} \mathrm{T}$ and $\mathrm{CD} 4^{+} \mathrm{T}$ cells could markedly suppress tumor formation and deterioration in tumor-bearing nude mice. (A) Tumor diameter of each experimental group two weeks after subcutaneous injection. (B) Tumor diameter of each experimental group two weeks after intratumorally injection. (C) Tumor weight of each experimental group two weeks after subcutaneous injection. (D) Tumor weight of each experimental group two weeks after intratumorally injection. There were ten nude mice in each group, mice in naive group ('model') were treated with an equal volume of PBS. "*** $\mathrm{p}<0.001$, ${ }^{* *} \mathrm{p}<0.01,{ }^{*} \mathrm{p}<0.05$ compared with model (naive) group. Three independent experiments were performed with similar results.

AFP and peptide/DC groups showed no differences for FasL expression (Fig. 4).

AFP-specific $C D 8^{+}$T and $C D 4^{+}$T cells suppress tumor formation and tumor growth in tumor-bearing nude mice. To further investigate the anti-tumor activity of DC activated AFP-specific T cells in vivo, human HCC xenograft-bearing nude mice were chosen as a model. Because the data above indicated that LentiAFP-DCs were superior in general to several peptides pulsed onto DC, and peptides 1-9 and 542-550 were superior among the subdominant (1-9) and immuno-dominant (542-550) peptides, we chose those groups to test in vivo.

First, we investigated the influence of AFP-specific T cells on tumor formation when simultaneously injected. Nude mice were treated by subcutaneous injection of HepG2 cells and AFP-specific CD8 ${ }^{+}$T cells \pm CD4 ${ }^{+}$T cells $(H e p G 2:$ T cell $=1: 1$ ). As shown in Fig. 5A and C, two weeks after tumor injection, (diameter $12.28 \pm 3.49 \mathrm{~mm}$; tumor weight $0.478 \pm 0.225 \mathrm{~g}$ ), symptoms was markedly ameliorated in Lenti-AFP and $\mathrm{AFP}_{542^{-}}$ treated group (Lenti-AFP: diameter $7.03 \pm 2.78 \mathrm{~mm}$, tumor weight $0.228 \pm 0.132 \mathrm{~g}, \mathrm{p}<0.01 ; \mathrm{AFP}_{542}$ : diameter $8.87 \pm 3.49 \mathrm{~mm}$, tumor weight $0.298 \pm 0.099 \mathrm{~g}, \mathrm{p}<0.05$ ), while $\mathrm{AFP}_{1}$-pulsed DCs activated $\mathrm{T}$ cells were less effective at reducing tumor growth.

Next, we examined the influence of AFP-specific T cells on established tumor growth (Fig. 5B and D). When the largest diameter of the injected HepG 2 tumor exceeded $3 \mathrm{~mm}$, mice were injected intratumorally with $10^{6}$ AFP-specific $\mathrm{CD}^{+} \mathrm{T}$ cells $\pm \mathrm{CD} 4^{+} \mathrm{T}$ cells. Mice were treated once a week for two weeks. At the end of the experiment, tumors were collected for tumor diameter and weight measures. Results suggested that, in comparison with negative control group, both Lenti-AFP and $\mathrm{AFP}_{542}$-treated groups could significantly reduce the tumor growth rate $(\mathrm{p}<0.01)$, consistently, by both measures.

Serum levels of several cytokines and molecules tested in vitro and important for anti-tumor immunity were also assessed. Results demonstrated (Fig. 6), that there were significant increases of systemic IL- 2 , IFN- $\gamma$, TNF- $\alpha$, perforin and Granzyme B in the three experimental groups, with a similar pattern of hierarchy $(\mathrm{p}<0.05)$ to the tumor volumes in Fig. 5, implicating these molecules in the possible mechanism of the $\mathrm{T}$ cell anti-tumor effects. Importantly, consistent with in vitro experimental results, the IL-10 level was lowest in the Lenti-AFP-DC treated group. Serum FasL expression did not appear to play a role, in agreement with the in vitro data.

\section{Discussion}

Antigen presentation is a crucial step of $\mathrm{T}$ cell activation. Dendritic cells, which act to initiate immune responses, are the most powerful professional antigen presenting cells. They 
A
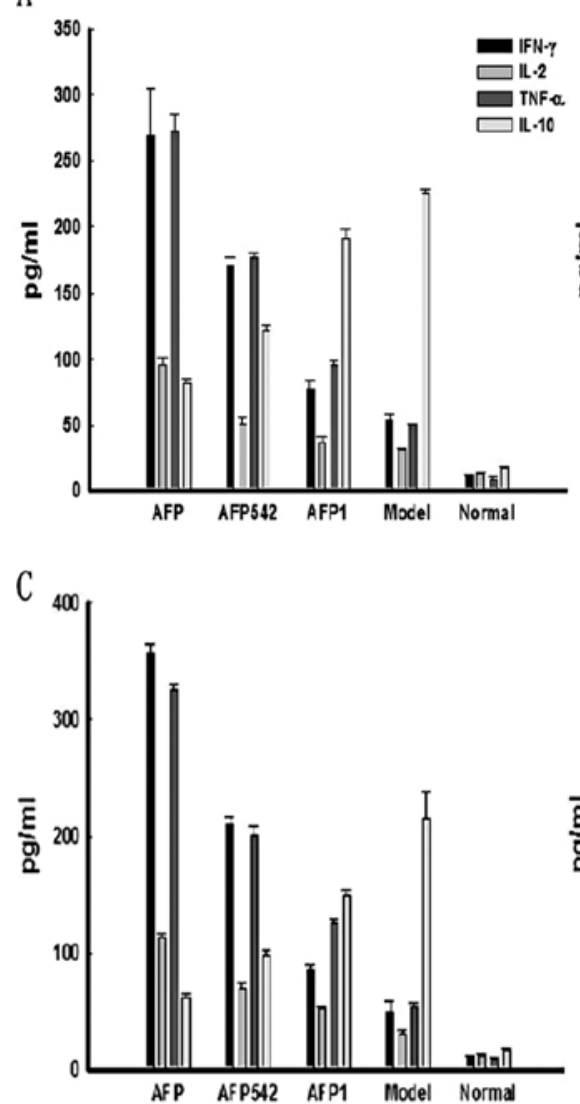

B
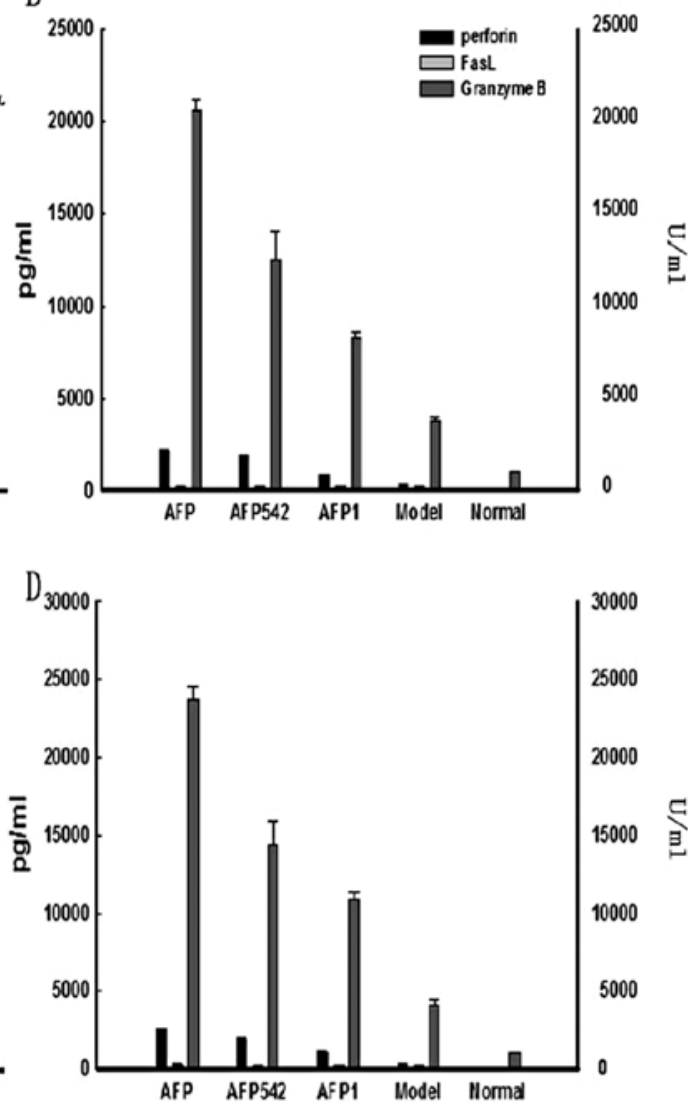

Figure 6. DC-based immunization results in modulated serum level of effector cytokines and anti-tumor molecules. (A) Serum concentration of IL-2, IFN- $\gamma$, TNF- $\alpha$, IL-10 after subcutaneous DC vaccine injection. (B) Serum concentration of perforin, FasL, Granzyme B (U/ml) after subcutaneous injection. (C) Serum concentration of IL-2, IFN- $\gamma, \mathrm{TNF}-\alpha$, IL-10 after intratumorally injection. (D) Serum concentration of perforin, FasL, Granzyme B (U/ml) after intratumorally injection. Serum levels for untreated 'normal' mice, and tumor-bearing, PBS-treated ('model') mice are also shown. Results are shown as the mean \pm SD. Three independent experiments were performed with similar results.

are very plastic cells, and are affected by the context in which they are exposed to antigen. Recent studies find that both tumor and the tumor microenvironment, through multiple complex pathways, can adversely affect DC in cancer patients; inhibiting DC maturation, and also reducing or even suppressing their antigen presentation function (30). Tumor can also promote immune tolerance to TAA by inducing the production of regulatory DC (31) and antigen-specific IL-10-producing Treg (32), which can further promote immune escape (33). Therefore, maintaining the appropriate balance between immune tolerance and immune activation is a pivotal focus for immunotherapy. Traditional approaches to DC modulation for improved anti-tumor immunity are mainly based on skewing DC maturation, to promote antigen-specific $\mathrm{CD}^{+} \mathrm{T}$ and $\mathrm{CD} 4^{+}$ $\mathrm{T}$ cells as well as innate effector responses that have type 1, anti-tumor activity (34-36). Such modified DC maturation methodology includes adding maturation agents like TLR agonists and cytokines to antigen sources like synthetic peptides, tumor homogenates or purified proteins when culturing DC in vitro (14), or directly transferring antigen into DC (17) via plasmids or viral vectors (37). In this study, we investigated the anti-tumor activity of AFP-specific $\mathrm{CD}^{+} \mathrm{T}$ cells, which were activated by AFP antigen, either loaded by MHC class I-restricted peptide-pulsing or lentivirus AFP-engineering of DC in vitro and in vivo. The in vitro experiments demonstrated that AFP-specific CD8 ${ }^{+} \mathrm{T}$ cells could proliferate, produce type 1 cytokines and efficiently kill HepG2 hepatocellular cancer cells, while the murine model demonstrated markedly suppressed tumor growth in HCC tumor-bearing nude mice.

We investigated cytokine production involved in anti-tumor immunity and changes induced by the different DC-based vaccines. Our findings demonstrate that AFP-specific T cells have significantly increased levels of IL-2, IFN- $\gamma$, TNF- $\alpha$, perforin and Granzyme B, a type 1, cytotoxic antitumor cytokine and effector molecule profile. Moreover, we examined IL-10, a negative regulator of $\mathrm{T}$ cell activation and which is up-regulated in HCC patients (38). Many previous studies have shown that addition of IL-10 neutralizing antibody to DC-T cell co-culture systems improves Th1 cell function (39). Such observations imply that reducing the level of IL-10 might have a positive effect on promoting anti-tumor immunity. Here, our results show that AFP-specific $\mathrm{CD}^{+} \mathrm{T}$ cells that are activated by Lenti-AFP-DC could markedly reduce IL-10 production, relative to other antigen loading strategies, like the commonly used peptide-pulsing method. This may be another mechanism for superior $\mathrm{T}$ cell activation.

Currently, two primary molecular mechanisms have been shown to play a role in CTL-induced target cell death: the Fas ligand/Fas pathway and the perforin/Granzyme B pathway 
(40). Both induce cell death directly in target cells via caspase activation. Hayashida et al (41) reported that perforin/Granzyme B played a dominant role on CTL-induced hepatocyte apoptosis. In this study, we examined the levels of perforin/ Granzyme B as well as FasL in both the human in vitro culture cell supernatant, as well as in murine serum from the HCC xenograft studies. Our results show that AFP-specific T cells could significantly upregulate both perforin and Granzyme B, while they had little effect on FasL. Thus, we conclude that the anti-tumor activity of the AFP-specific T cells activated both in vitro and in vivo involved the perforin/Granzyme B pathway. Lastly, our results show that AFP-specific $\mathrm{CD} 8^{+} \mathrm{T}$ cells groups which included $\mathrm{CD}^{+} \mathrm{T}$ cells revealed a reproducible trend towards stronger killing activity. Moreover, there was increased IL-2 production in the experimental groups including $\mathrm{CD} 4^{+} \mathrm{T}$ cells, indicating that inclusion of the $\mathrm{CD} 4^{+} \mathrm{T}$ cells have a helper role for the anti-tumor activity.

In summary, the data presented here demonstrate that lentivirus-engineered DC activate AFP-specific T cells, reveal potent in vitro and in vivo anti-tumor activity, and may be a promising approach for HCC immunotherapy in patients.

\section{Acknowledgements}

This study was supported by the University of Pittsburgh Cancer Institute and RO1- CA104524 (LHB) and by Shanghai Pu Jiang Talented Person Plan of China \#07PJ14004 (YL).

\section{References}

1. Levin B and Amos C: Therapy of unresectable hepatocellular carcinoma [editorial; comment] [published erratum appears in $\mathrm{N}$ Engl J Med 333: 675, 1995]. N Engl J Med 332: 1294-1296, 1995.

2. Fisher RA, Maroney TP, Fulcher AS, et al: Hepatocellular carcinoma: strategy for optimizing surgical resection, transplantation and palliation. Clin Transplant 16 (Suppl 7): 52-58, 2002.

3. Rosenberg SA: Progress in human tumour immunology and immunotherapy. Nature 411: 380-384, 2001.

4. Abelev GI and Eraiser TL: Cellular aspects of alpha-fetoprotein reexpression in tumors. Semin Cancer Biol 9: 95-107, 1999.

5. Isaacs H Jr: Fetal and neonatal hepatic tumors. J Pediatr Surg 42: 1797-1803, 2007.

6. Mizejewski GJ: Biological role of alpha-fetoprotein in cancer: prospects for anticancer therapy. Expert Rev Anticancer Ther 2 : 709-735, 2002

7. Kubota M, Yagi M, Kanada S, et al: Effect of postoperative chemotherapy on the serum alpha-fetoprotein level in hepatoblastoma. J Pediatr Surg 39: 1775-1778, 2004.

8. Nakagawara A, Ikeda K, Tsuneyoshi M, et al: Hepatoblastoma producing both alpha-fetoprotein and human chorionic gonadotropin. Clinicopathologic analysis of four cases and a review of the literature. Cancer 56: 1636-1642, 1985.

9. Banchereau J and Steinman RM: Dendritic cells and the control of immunity. Nature 392: 245-252, 1998.

10. Fong L, Brockstedt D, Benike C, Wu L and Engleman EG: Dendritic cells injected via different routes induce immunity in cancer patients. J Immunol 166: 4254-4259, 2001.

11. Ladanyi A, Kiss J, Somlai B, et al: Density of DC-LAMP(+) mature dendritic cells in combination with activated $\mathrm{T}$ lymphocytes infiltrating primary cutaneous melanoma is a strong independent prognostic factor. Cancer Immunol Immunother 56 : $1459-1469,2007$.

12. Verra N, de Jong D, Bex A, et al: Infiltration of activated dendritic cells and $\mathrm{T}$ cells in renal cell carcinoma following combined cytokine immunotherapy. Eur Urol 48: 527-533, 2005.

13. Rasaiyaah J, Noursadeghi M, Kellam P and Chain B: Transcriptional and functional defects of dendritic cells derived from the MUTZ-3 leukaemia line. Immunology 127: 429-441, 2009.
14. Butterfield LH, Meng WS, Koh A, et al: T cell responses to HLA-A*0201-restricted peptides derived from human alpha fetoprotein. J Immunol 166: 5300-5308, 2001.

15. Butterfield LH, Koh A, Meng W, et al: Generation of human T-cell responses to an HLA-A2.1-restricted peptide epitope derived from alpha-fetoprotein. Cancer Res 59: 3134-3142, 1999.

16. Butterfield LH, Ribas A, Meng WS, et al: T-cell responses to HLA-A*0201 immunodominant peptides derived from alphafetoprotein in patients with hepatocellular cancer. Clin Cancer Res 9: 5902-5908, 2003.

17. Meng WS, Butterfield LH, Ribas A, et al: alpha-Fetoproteinspecific tumor immunity induced by plasmid prime-adenovirus boost genetic vaccination. Cancer Res 61: 8782-8786, 2001.

18. Vollmer CM Jr, Eilber FC, Butterfield LH, et al: Alphafetoprotein-specific genetic immunotherapy for hepatocellular carcinoma. Cancer Res 59: 3064-3067, 1999.

19. Butterfield LH, Ribas A, Dissette VB, et al: A phase I/II trial testing immunization of hepatocellular carcinoma patients with dendritic cells pulsed with four alpha-fetoprotein peptides. Clin Cancer Res 12: 2817-2825, 2006.

20. Butterfield LH, Ribas A, Potter DM and Economou JS: Spontaneous and vaccine induced AFP-specific T cell phenotypes in subjects with AFP-positive hepatocellular cancer. Cancer Immunol Immunother 56: 1931-1943, 2007.

21. Liu Y, Daley S, Evdokimova VN, Zdobinski DD, Potter DM and Butterfield LH: Hierarchy of alpha fetoprotein (AFP)-specific T cell responses in subjects with AFP-positive hepatocellular cancer. J Immunol 177: 712-721, 2006.

22. Gonzalez-Carmona MA, Marten A, Hoffmann P, et al: Patientderived dendritic cells transduced with an $\alpha$-fetoprotein-encoding adenovirus and co-cultured with autologous cytokine-induced lymphocytes induce a specific and strong immune response against hepatocellular carcinoma cells. Liver Int 26: 369-379, 2006.

23. Naldini L: Lentiviruses as gene transfer agents for delivery to non-dividing cells. Curr Opin Biotechnol 9: 457-463, 1998.

24. Arthur JF, Butterfield LH, Roth MD, et al: A comparison of gene transfer methods in human dendritic cells. Cancer Gene Ther 4: 17-25, 1997.

25. Romani N, Gruner S, Brang D, et al: Proliferating dendritic cell progenitors in human blood. J Exp Med 180: 83-93, 1994.

26. Plebanski M, Allsopp CE, Aidoo M, Reyburn H and Hill AV: Induction of peptide-specific primary cytotoxic T lymphocyte responses from human peripheral blood. Eur J Immunol 25: 1783-1787, 1995.

27. Butterfield LH, Jilani SM, Chakraborty NG, et al: Generation of melanoma-specific cytotoxic $\mathrm{T}$ lymphocytes by dendritic cells transduced with a MART-1 adenovirus. J Immunol 161: 5607-5613, 1998.

28. Mukherji B, Guha A, Chakraborty NG, Sivanandham M, Nashed AL, Sporn JR and Ergin MT: Clonal analysis of cytotoxic and regulatory $\mathrm{T}$ cell responses against human melanoma. J Exp Med 169: 1961-1976, 1989

29. Schumacher L, Ribas A, Dissette VB, McBride WH, Mukherji B, Economou JS, et al: Human dendritic cell maturation by adenovirus transduction enhances tumor antigen-specific T-cell responses. J Immunother 27: 191-200, 2004.

30. Zhang Z, Liu Q, Che Y, et al: Antigen presentation by dendritic cells in tumors is disrupted by altered metabolism that involves pyruvate kinase M2 and its interaction with SOCS3. Cancer Res 70: 89-98, 2010.

31. Schakel K: Dendritic cells - why can they help and hurt us. Exp Dermatol 18: 264-273, 2009.

32. Vence L, Palucka AK, Fay JW, Ito T, Liu YJ, Banchereau J, et al: Circulating tumor antigen-specific regulatory $\mathrm{T}$ cells in patients with metastatic melanoma. Proc Natl Acad Sci USA 104: 20884-20889, 2007

33. Chaput N, Conforti R, Viaud S, Spatz A and Zitvogel L: The Janus face of dendritic cells in cancer. Oncogene 27: 5920-5931, 2008.

34. Vujanovic L, Szymkowski DE, Alber S, Watkins SC, Vujanovic NL and Butterfield LH: Virally infected and matured human dendritic cells activate natural killer cells via cooperative activity of plasma membrane-bound TNF and IL-15. Blood 116: 575-583, 2010.

35. Mailliard RB, Wankowicz-Kalinska A, Cai Q, Wesa A, Hilkens CM, Kapsenberg ML, et al: alpha-type-1 polarized dendritic cells: a novel immunization tool with optimized CTL-inducing activity. Cancer Res 64: 5934-5937, 2004. 
36. Tatsumi T, Kierstead LS, Ranieri E, Gesualdo L, Schena FP, Finke JH, et al: Disease-associated bias in Thelper type 1 (Th1)/ Th2 CD4(+) T cell responses against MAGE-6 in HLADRB10401(+) patients with renal cell carcinoma or melanoma. J Exp Med 196: 619-628, 2002.

37. Meng WS and Butterfield LH: Activation of antigen-presenting cells by DNA delivery vectors. Expert Opin Biol Ther 5: 1019-1028, 2005.

38. Beckebaum S, Zhang X, Chen X, Yu Z, Frilling A, Dworacki G, et al: Increased levels of interleukin-10 in serum from patients with hepatocellular carcinoma correlate with profound numerical deficiencies and immature phenotype of circulating dendritic cell subsets. Clin Cancer Res 10: 7260-7269, 2004.
39. De Smedt T, Van Mechelen M, De Becker G, Urbain J, Leo O and Moser M: Effect of interleukin-10 on dendritic cell maturation and function. Eur J Immunol 27: 1229-1235, 1997.

40. Berke G: The CTL's kiss of death. Cell 81: 9-12, 1995.

41. Hayashida M, Kawano H, Nakano T, Shiraki K and Suzuki A: Cell death induction by CTL: perforin/granzyme B system dominantly acts for cell death induction in human hepatocellular carcinoma cells. Proc Soc Exp Biol Med 225: 143-150, 2000 . 